\title{
Possible Association between the Lack of Regular Physical Activity with Tinnitus and Headache: Cross-sectional Study
}

\author{
Jéssica Aparecida Bazoni ${ }^{1}$ Ana Carolina Marcotti Dias ${ }^{10}$ Caroline Luiz Meneses-Barriviera ${ }^{1}$ \\ Luciana Lozza de Moraes Marchiori ${ }^{1}$ Denilson de Castro Teixeira ${ }^{2}$
}

\footnotetext{
${ }^{1}$ Doctoral and Masters Programs in Rehabilitation Sciences, Universidade Estadual de Londrina, Unopar, Londrina, PA, Brazil

${ }^{2}$ Department of Physical Education, Universidade Estadual de Londrina, Londrina, PA, Brazil
}

\author{
Address for correspondence Ana Carolina Marcotti Dias, \\ Universidade Norte do Paraná - UNOPAR, Centro de Ciências da \\ Reabilitação, Rua Marselha, Londrina 86041-120, Brazil \\ (e-mail: acmarcotti@hotmail.com).
}

Int Arch Otorhinolaryngol 2019;23:e375-e379.

\begin{abstract}
Keywords

- tinnitus

- aging

- exercise

- headache
\end{abstract}

\section{Introduction}

There is a significant relationship between tinnitus and headache, as well as interaction of symptoms over time, and argue against a purely coincidental co-occurrence of tinnitus and headache. Moreover, there is increasing evidence that, in some cases, both disorders may be linked by common pathophysiological mechanisms. ${ }^{1}$ Physical activity is defined as any bodily movement produced by skeletal muscles that results in energy expenditure beyond resting expenditure. Exercise is a subset of physical activity that is planned, structured, repetitive, and purposefully planned to maintain conditioning. ${ }^{2}$ Physical inactivity is a primary cause of most chronic diseases. Taken together, conclusive evidence exists that physical inactivity is one important cause of most chronic diseases. In addition, physical activity primarily prevents, or delays, chronic diseases, metabolic, and circulatory changes that cause several symptoms. ${ }^{3}$

In a cross-sectional study involving Brazilian individuals $>60$ years old, of the $42.77 \%$ that reported tinnitus, $58.68 \%$ presented with bilateral tinnitus, and $41.31 \%$ presented with received

March 28, 2017

accepted

March 18, 2019
DOI https://doi.org/

10.1055/s-0039-1688469. ISSN 1809-9777.
Copyright (e 2019 by Thieme Revinter

Publicações Ltda, Rio de Janeiro, Brazil
License terms

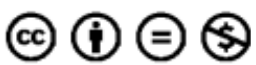


unilateral tinnitus. ${ }^{4}$ In a study involving people $>65$ years old in the city of São Paulo, state of São Paulo, Brazil, the prevalence (mean and $95 \%$ confidence interval $[\mathrm{CI}]$ ) of any type of headache in the previous year was of $45.6 \%$ (95\% CI: $43.2-48.0 \%$ ). The prevalence of tension-type headache in the previous year was of $33.1 \%$ (95\% CI: $30.8-35.4 \%$ ); of $28.1 \%$ (95\% CI: $24.6-$ $31.6 \%$ ) for men, and of $36.4 \%$ (95\% CI: 33.4-39.4\%) for women; for migraine headaches, the prevalence in the previous year was of $10.6 \%$ (95\% CI: $9.1-12.1 \%$ ): of $5.1 \%$ (95\% CI: 3.4-6.8\%) for men, and of $14.1 \%$ (95\% CI: $11.9-16.3 \%)$ for women. ${ }^{5}$ There have been few recent estimates of the prevalence of tinnitus from population-based samples of older individuals. ${ }^{6}$

Especially in the elderly, lack of regular physical activity and low degree of physical conditioning are risk factors for several metabolic and circulatory changes that cause various symptoms, such as headache, hearing loss, vertigo and tinnitus. ${ }^{3,7}$ According to Simmons et al, ${ }^{8}$ recent functional brain imaging studies in humans suggest that the neural generators for tinnitus may reside in the central nervous system (CNS) and involve both auditory and nonauditory centers, and that many patients have somatic tinnitus whereby movements and manipulations of the eyes, head, neck, jaw, and shoulder can modulate the loudness and pitch of their tinnitus. In most cases, the maneuvers lead to an increase in the loudness or in the pitch of the tinnitus, rather than decreasing them. In a study of the association between headaches and tinnitus in young adults, tinnitus was reported by $8.9 \%$ of the participants with migraine, in $7.3 \%$ of the patients with migraine without aura, and in $10.8 \%$ of the participants with migraine with aura. An association between migraine and tinnitus among young individuals was found, being strongest among the migraine with aura subgroup. ${ }^{9}$ In a study of the association between tinnitus and headache, it was demonstrated that only in $15 \%$ of the cases tinnitus appeared by itself without being associated with headache in adults. ${ }^{10}$

From the present literature review, the central hypothesis of the present work determines that the presence of tinnitus and headache may be associated with the lack of regular physical activity among elderly patients. Based on the considerations presented, the present study aimed to investigate the possible association between the presence of tinnitus and headache by associating it with the lack of regular physical activity among the elderly patients who participated in the present project.

\section{Method}

This was a cross-sectional study. The sample of the present research was selected by convenience from an interdisciplinary project called the project study EELO, which was developed at the Universidade do Norte Paraná - UNOPAR, after approval by the Research Ethics Committee of that institution. The present study was a substudy of a prospective, cross-sectional study of EELO. The city of Londrina (counting with $\sim 500,000$ inhabitants) is situated in the north region of Paraná state, Brazil.

There are 43.610 elderly people enrolled in the 38 primary care units in the urban city area. The sample was a randomly stratified set, considering the gender and the 5 areas of the city
(15\% from the central area, 27\% from the northern area, $23 \%$ from the southern area, $19 \%$ from the eastern area, and $16 \%$ from the western area). The study included individuals aged $\geq 60$ years old, of both genders, who were living independently and were classified at level 3 or 5 , as proposed by Spirduso. ${ }^{11}$ This classification evaluates the independence level of the elderly, with level one indicating a lack of self-mobility, and level five indicating athletes. Elderly people who had any illness or limitation that would prevent the testing, such as physical or mental disabilities, were excluded from the sample. All of the participants signed an informed consent form. A sample of 494 elderly individuals was included in this part of the study.

The regular practice of physical activity was verified by means of the following objective questions: "Do you, Mr./Mrs., practice any regular physical activity? If so, since when do you practice it, how often and for how long (at least 30 minutes a day)?" A questionnaire including questions about age, gender, tinnitus, headache, and comorbidities based on the protocol for anamnesis by Miller ${ }^{12}$ was applied in the present study.

The analysis was conducted with nonparametric tests: chisquared $\left(X^{2}\right)$ to determine possible associations between tinnitus and headache in individuals with lack of regular physical activity. The value of $p<0.05$ with a $95 \% \mathrm{CI}$ was considered for the univariate analysis for inclusion in the final model of the $X^{2}$ test and the relative risk (RR). A multiple logistic regression model was used to determine how well each factor predicted headache while controlling for each of the other factors. The tests were performed using the BioEstat 5.0 software (Instituto de Desenvolvimento Sustentável Mamirauá, Belém, PA, Brazil).

\section{Results}

Based on a sample of 494 subjects, of which 331 were females and 163 were males, it was found that 213 (43.11\%) complained of tinnitus. Among the complainants, 97 (45.53\%) practiced physical activity. In the analysis of the whole sample (494 subjects), the chi-squared test resulted in $X^{2}=0.501$; $p=0.5375$, showing no statistically significant association between tinnitus alone and physical activity ( Table $\mathbf{1}$ ).

The lack of association was also confirmed by the analysis by gender: among the female subjects $(n=331)$, the statistic was $\mathrm{X}^{2}=0.134 ; p=0.7997$; and among the male subjects $(n=163), \mathrm{X}^{2}=3.091 ; p=0.1099$.

Table 1 Thorough distribution of patients according to the practice of physical activity and tinnitus

\begin{tabular}{|l|l|l|l|l|l|}
\hline \multirow{3}{*}{$\begin{array}{l}\text { Physical } \\
\text { activity }\end{array}$} & \multicolumn{4}{|l|}{ Complaint of tinnitus } & \multirow{2}{*}{ Total } \\
\cline { 2 - 5 } & Yes & \multicolumn{2}{|l|}{ No } & \\
\cline { 2 - 5 } & $n$ & $\%$ & $n$ & $\%$ & \\
\hline Yes & 97 & 19.64 & 119 & 24.09 & 216 \\
\hline No & 116 & 23.48 & 162 & 32.79 & 278 \\
\hline Total & 213 & & 281 & & 494 \\
\hline
\end{tabular}

Odds ratio $=1.1384 ; 95 \%$ confidence interval: $0.7952-1.6297$; absolute risk reduction $=3.19 \%$; number needed to harm $=32$; chi-squared correlation coefficient $=0.501(p=0.5375)$ 
Table 2 Thorough distribution of patients according to the practice of physical activity and headache

\begin{tabular}{|l|l|l|l|l|l|}
\hline \multirow{3}{*}{$\begin{array}{l}\text { Physical } \\
\text { activity }\end{array}$} & \multicolumn{2}{|l|}{ Headache } & \multirow{2}{*}{ Total } \\
\cline { 2 - 5 } & \multicolumn{2}{|l|}{ Yes } & No & \\
\cline { 2 - 5 } & $n$ & $\%$ & $n$ & $\%$ & \\
\hline Yes & 78 & 42,16 & 138 & 45,39 & 216 \\
\hline No & 107 & 57,83 & 166 & 54,60 & 273 \\
\hline Total & 185 & & 304 & & 489 \\
\hline
\end{tabular}

Odds ratio $=0,8769 ; 95 \%$ confidence interval: $0,606-1,2682$; absolute risk reduction $=3.08 \%$; number needed to treat $=33$; chi-squared test $=0.487(p=0.4851)$

For the statistical analysis of the complainants of both tinnitus and headache, the subjects that did not completely answer the questionnaires were excluded, thus totaling 489 subjects.

Of these 489 subjects, 185 (37.83\%) complained of having headache. Of the 185 with headache, 78 practiced regular physical activity (42.16\%). Of the 304 without complaint of headache, 138 practiced regular physical activity (45.39\%). The chi-squared test resulted in $X^{2}=0.487 ; p=0.4851$, showing no statistically significant association between headache alone and physical activity (-Table 2 ).

From this sample of 489 subjects, 210 (42.94\%) complained of tinnitus. Of the 210 patients with tinnitus, 99 also presented with headache, of which 61 (61.61\%) did not perform any physical activity. We have verified possible associations between headache and lack of physical activity among elderly individuals with tinnitus ( $p=0.0440)$. ( - Table 3 ).

Of these 489 subjects, 127 (25.97\%) reported a history of occupational noise exposure, and 362 subjects (74.02\%) did not.

A multiple logistic regression was performed first, including the variables gender, age, tinnitus, physical activity, and headache of the total sample ( - Table 4 ); then, a multiple logistic regression was performed with the exclusion of all individuals who had a history of working in noisy environments and with the inclusion of the variables gender, age, tinnitus, physical activity, and headache (-Table 5).

In both regression analyses, we found equivalent results, suggesting that occupational noise exposure does not inter-

Table 3 Thorough distribution of the number of patients complaining of tinnitus in relation to physical activity and headache

\begin{tabular}{|l|l|l|l|l|l|}
\hline \multirow{2}{*}{ Physical activity } & \multicolumn{3}{|l|}{$\begin{array}{l}\text { 210 patients complaining of } \\
\text { tinnitus }\end{array}$} & \\
\cline { 2 - 5 } & \multicolumn{2}{|l|}{ Headache } & \multirow{2}{*}{ Total } \\
\cline { 2 - 5 } & Yes & \multicolumn{2}{|l|}{ No } & \\
\cline { 2 - 5 } & $\boldsymbol{n}$ & $\%$ & $n$ & $\%$ & \\
\hline Yes & 38 & 38,38 & 58 & 52,25 & 96 \\
\hline No & 61 & 61,61 & 53 & 47,74 & 114 \\
\hline Total & 99 & 47,14 & 111 & 52,85 & 210 \\
\hline
\end{tabular}

Odds ratio $=0.5692 ; 95 \%$ confidence interval: 0.3283-0.9869); absolute risk reduction $=13.93 \%$; number needed to harm $=8$; chisquared test $=4.056(p=0.0440)$ fere in the findings regarding the correlation found. It could be observed that male gender and tinnitus are independent factors for the complaint of headache.

\section{Discussion}

The analysis was conducted to determine whether the presence of tinnitus and headache may be associated with the lack of regular physical activity in elderly patients. The results of the analysis partially supported the central hypothesis, being observed in the initial analysis a possible association between headaches and the lack of physical activity among elderly individuals with tinnitus. It has also been observed in the logistic regression analysis that certain factors, such as male gender and tinnitus, are independent factors for the complaint of headache.

This is possibly justified in that physical inactivity may be an important risk factor for diseases. Sedentary lifestyle may accelerate the aging process and increase the risk of comorbidities. ${ }^{13}$ In a study with the same population, the presence of complaint of vertigo was lower among elderly individuals who were practitioners of regular physical activity. It verified that there was a significant association ( $p=0.001$ ) between the lack of regular physical activity and vertigo, and that people who do not practice regular physical activities are 2.38 times more likely to have vertigo than those who engage in regular physical activity. $^{14}$

We have found in our study that headache was present in $47.14 \%$ of the sample with tinnitus, and was more prevalent in those with lack of regular physical activity, that is, in $61.61 \%$ of them. This high prevalence may be related to the large number of metabolic and circulatory changes and to the emotional factors present in this population, especially in those without regular physical activity.

In the literature, the etiopathogenesis of tinnitus associated with headache has been attributed to lifestyle habits, clinical conditions, vascular and neuropeptide mechanisms, with even the psychological component appearing to play a role in triggering the event. ${ }^{9,10}$

In an analytical cross-sectional study, part of the Amirkola Health and Aging Project to determine the associated factors of headache in elderly subjects, the results of the logistic regression analysis after adjustment for all covariates demonstrated a significant independent association between headache, female gender, back pain, and depression. ${ }^{15}$ Thus, it presented a different result from our study, which demonstrates males as an independent risk factor for headache.

In a study that analyzed the prevalence and associated risk factors of tinnitus, using data from the Korea National Health and Nutrition Examination Survey, the results demonstrated a significant association between tinnitus, female gender, stress, unemployment, hyperlipidemia, osteoarthritis, rheumatoid arthritis, asthma, depression, thyroid disease, hearing loss, noise exposure with earphones, noise exposure at the workplace, noise exposure at locations other than the workplace, and brief noise exposure. ${ }^{16}$ In our study, we 
Table 4 Multiple logistic regression was performed first, including the variables gender, age, tinnitus, physical activity and headache of the total sample

\begin{tabular}{|c|c|c|c|c|c|}
\hline \multicolumn{6}{|c|}{ Multiple Logistic Regression } \\
\hline \multicolumn{6}{|l|}{ Total sample } \\
\hline Variables & Coefficient & Standard error & p-value & Odds ratio & $95 \% \mathrm{Cl}$ \\
\hline Intercept / headache & 0.9262 & 1.0739 & $\ldots$ & $\ldots$ & $\ldots$ \\
\hline Age $(x 1)$ & -0.0204 & 0.0154 & 0.1855 & 0.9798 & $0.95-1.01$ \\
\hline Gender (x2) & -0.8829 & 0.2186 & 0.0001 & 0.4136 & $0.27-0.63^{*}$ \\
\hline Tinnitus (x3) & 0.7432 & 0.1946 & 0.0001 & 2.1026 & $1.44-3.08^{*}$ \\
\hline Physical activity (x4) & -0.1617 & 0.1950 & 0.4068 & 0.8507 & $0.58-1.25$ \\
\hline
\end{tabular}

Abbreviation: $\mathrm{Cl}$, confidence interval.

$p \leq 0.05$ (indicated in bold).

Table 5 Multiple logistic regression with the exclusion of all individuals who had a history of working in noisy environments

\begin{tabular}{|c|c|c|c|c|c|}
\hline \multicolumn{6}{|c|}{ Multiple Logistic Regression } \\
\hline \multicolumn{6}{|c|}{ Excluding subjects with a history of occupational noise exposure } \\
\hline Variables & Coefficient & Standard error & p-value & Odds ratio & $95 \% \mathrm{Cl}$ \\
\hline Intercept / headache & 0.1347 & 1.2044 & $\ldots$ & $\ldots$ & $\ldots$ \\
\hline Age $(x 1)$ & -0.0077 & 0.0173 & 0.6574 & 0.9924 & $0.96-1.03$ \\
\hline Gender (x2) & -1.0398 & 0.3002 & 0.0005 & 0.3535 & $0.20-0.64^{*}$ \\
\hline Tinnitus (x3) & 0.6717 & 0.2250 & 0.0028 & 1.9575 & $1.26-3.04 *$ \\
\hline Physical activity (x4) & -0.2653 & 0.2249 & 0.2383 & 0.7670 & $0.49-1.19$ \\
\hline
\end{tabular}

Abbreviation: $\mathrm{Cl}$, confidence interval.

${ }^{*} \mathrm{p} \leq 0.05$ (indicated in bold).

observed that occupational noise exposure does not interfere in the findings regarding the correlation of tinnitus and headache associated with the lack of regular physical activity among elderly patients.

Sedentary lifestyle contributes to chronic diseases and is probably associated with the symptoms caused by these complex polygenic conditions. The physical activity can primarily prevent between $20-30 \%$ of depression and its symptoms. $^{3}$

Studies also suggest that the sedentary lifestyle has a large impact as a cause of chronic diseases and its symptoms (depression, tinnitus, headache), that may be linked to each other by common pathophysiological mechanisms. ${ }^{1,3,15,16}$

The present study had some limitations that should be considered. A potential limitation of the present study stems from its observational nature and the self-reported survey that may not capture the actual amount of regular physical activity of the subjects. Because of these limitations, future researches should be performed, by means of case-control or population-based studies, to confirm the prevalence rates of headache and tinnitus among elderly people lacking regular physical activity. Further researches are needed to investigate the mechanism of this association, using longitudinal data with a prospective design and additional clinical examination to examine the connection between physical activity, headache, and tinnitus throughout the lifetime of an individual.

\section{Conclusion}

By the application of the chi-squared test $\left(x^{2}\right)$ allows It was determined if the two variables, lack of regular physical activity and headache, were associated. We found that headache may be a symptom related to the lack of regular physical activity among elderly with tinnitus. It has also been observed that certain factors, such as gender and tinnitus, are independent factors for headache complaint.

The present study suggests the relevance of further prospective studies aiming at determining the relationship between improvement in tinnitus and headache and physical activities in general, and more specifically with certain modalities of physical exercises tinnitus and headache with regular physical activity. Further studies will be necessary to develop a method of prevention and rehabilitation from tinnitus and headache by means of physical activity.

Hearing loss should be considered as a variable of confusion that may influence the relationship between tinnitus, headache, and exercise, and should be considered in future studies.

\section{Funding}

The present study received funding by the Fundação Nacional de Desenvolvimento do Ensino Superior (FUNADESP, in the Portuguese acronym) for research support. 


\section{Conflicts of Interests}

The authors have no conflicts of interests to declare.

\section{References}

1 Langguth B, Hund V, Busch V, et al. Tinnitus and Headache. BioMed Res Int 2015;2015:797416

2 De Feo P, Schwarz P. Is physical exercise a core therapeutical element for most patients with type 2 diabetes? Diabetes Care 2013;36(36, Suppl 2):S149-S154

3 Booth FW, Roberts CK, Laye MJ. Lack of exercise is a major cause of chronic diseases. Compr Physiol 2012;2(02):1143-1211

4 Gibrin PC, Melo JJ, Marchiori LL. Prevalência de queixa de zumbido e prováveis associações com perda auditiva, diabetes mellitus e hipertensão arterial em pessoas idosas. CoDAS 2013;25(02): 176-180

5 Benseñor IM, Lotufo PA, Goulart AC, Menezes PR, Scazufca M. The prevalence of headache among elderly in a lowincome area of São Paulo, Brazil. Cephalalgia 2008;28(04):329333

6 Sindhusake D, Mitchell P, Newall P, Golding M, Rochtchina E, Rubin G. Prevalence and characteristics of tinnitus in older adults: the Blue Mountains Hearing Study. Int J Audiol 2003;42(05): 289-294

7 Marchiori LLM. Zumbido e hipertensão arterial no processo de envelhecimento. Rev Bras Hipertens. 2009;16:5-8
8 Simmons R, Dambra C, Lobarinas E, Stocking C, Salvi R. Head, Neck, and Eye Movements That Modulate Tinnitus. Semin Hear 2008;29(04):361-370

9 Guichard E, Montagni I, Tzourio C, Kurth T. Association Between Headaches and Tinnitus in Young Adults: Cross-Sectional Study. Headache 2016;56(06):987-994

10 Farri A, Enrico A, Lacilla M, Sartoris A. [Tinnitus during headache: clinical-instrumental evaluation]. Acta Otorhinolaryngol Ital 1999;19(02):70-75

11 Spidurso WW. Dimensões físicas do envelhecimento. Barueri: Manole; 2005

12 Miller MH. A integração dos achados audiológicos. In: Katz J(Org). Tratado de audiologia clínica. 3rd ed. São Paulo: Manole; 1999. chap. $13,268-70$

13 Cherkas LF, Hunkin JL, Kato BS, et al. The association between physical activity in leisure time and leukocyte telomere length. Arch Intern Med 2008;168(02):154-158

14 Bazoni JA, Mendes WS, Moreira MD, Melo JJ, Meneses-Barriviera CL, T. D. C. et al. Vertigo complaint and regular physical activity in the elderly. Rev CEFAC 2013;15(06):1447-1452

15 Ahmadi Ahangar A, Hossini SR, Kheirkhah F, Bijani A, Moghaddas Z. Associated factors of headache in an unstudied cohort of elderly subjects. Caspian J Intern Med 2016;7(02):120-125

$16 \mathrm{Kim} \mathrm{HJ}$, Lee HJ, An SY, et al. Analysis of the prevalence and associated risk factors of tinnitus in adults. PLoS One 2015;10 (05):e0127578 